\title{
Nanoparticles for Two-photon Photodynamic Therapy in Living Cells
}

\author{
De Gao ${ }^{1}$, Rodney R. Agayan ${ }^{1,2}$, Hao Xu ${ }^{3}$, Martin A. Philbert ${ }^{3}$, and Raoul Kopelman ${ }^{1,2}$ \\ 1 Department of Chemistry, University of Michigan, Ann Arbor, MI 48109-1055 \\ 2 Department of Applied Physics, University of Michigan, Ann Arbor, MI 48109-1120 \\ 3 Department of Environmental Health Sciences, University of Michigan, Ann Arbor, MI 48109-2029
}

\begin{abstract}
We describe here a non-toxic two-photon photodynamic nanoparticle-platform and its cellular application. We dem onstrate that the dye's potential toxicity can be circumvented by its permanent encapsulation into a bio-compatible nanoparticle polymer matrix; this was examined by dye leaching experiments and confirmed by cell uptake experiments. Infra-red two-photon nanoplatform phototoxicity was demonstrated for rat C6 glioma cells, while the controls showed no dark toxicity for these living cells.
\end{abstract}

\begin{abstract}
Brain cancers are the most aggressive human cancers. No single treatment has yet been found to arrest the fast growth of malignant gliomas. Photodynamic therapy (PDT), a light-activated chemotherapeutic treatment, may be an effective approach, possibly in combination with others, such as neurosurgical operative techniques and radiotherapy. In PDT, irradiated photosensitizers that surround or enter cells transfer their energy to molecular oxygen, thus forming highly reactive singlet oxygen $\left({ }^{1} \mathrm{O}_{2}\right)$ and other reactive oxygen species which, in turn, kill the nearby cells. This method has been developed for the treatment of a variety of cancerous tumors ${ }^{1}$. Serious challenges arise, however, with the traditional single-photon PDT for glioma tissues $^{2}$. For example, currently approved single-photon PDT drugs have the drawback of requiring excitation by visible light, which has limited penetration depth due to the restrictive tissue transparency window for target cells that are located deep inside living tissues; photons in this spectral region don't penetrate deep enough, thus making single-photon PDT less effective for glioma tissue treatment. As an alternative method, two-photon PDT (TP-PDT) has many advantages than that of one-photon PDT. In TP-PDT, dye molecules can simultaneously absorb two less energetic photons to the excited electronic state. The excited molecules then react with oxygen to produce singlet oxygen. The excitation of two-photon dyes in the near-infrared region (tissue spectral window is between 800 and $1100 \mathrm{~nm}$ ) avoids tissue absorbing or scattering and makes it possible to treat deeper diseased tissues in vivo. However, the direct application of drugs to the brain is limited by the drug's distribution and toxicity. These drug molecules usually also harm normal cells even before they reach their target cells. For example, 5, 10, 15, 20-tetrakis (1-methyl 4-pyridinio) porphyrin tetra (ptoluenesulfonate) (TMPyP) is a positively charged molecule that can bind to DNA. In cultures it binds to negatively charged cell surfaces and then, it is internalized into the cells; the consequent binding between TMPyP and DNA affects cell viability ${ }^{3}$. Although several recent reports directly applied water-soluble dyes to living HeLa cells and YPEN-1 rat prostate endothelial cells ${ }^{4}$, the dyes' own toxicity to cells remains an open question.
\end{abstract}


Entrapping TP photo-sensitizers in biologically inert nanoparticles can eliminate or limit the photosensitizer's toxicity to normal cells, provide deeper light penetration, and cause less photo-damage to normal cells and tissues than single-photon PDT. Therefore, TP dyeencapsulating photodynamic nanoplatforms offer an avenue for circumventing the above problems. Various molecules with relatively large TP absorption cross sections have been designed as TP singlet oxygen sensitizers in order to achieve high TP quantum yield ${ }^{5}$. This made it possible for us to evaluate TP-PDT nanoplatforms for their toxicity and phototoxicity in living cells. The objective of the present study was the evaluation of TMPyP encapsulating nanoparticles as to both their dark toxicity and their TP-PDT efficiency for rat C6 glioma cells. This is the first investigation on such nanoplatform safety, as well as their TP-PDT, for glioma cell cultures, to the best of our knowledge. We demonstrate here that the long term encapsulation of a commercially available TP dye (TMPyP) by nanoparticles can prevent the dye from direct contact with cells but, at the same time, the dye can still kill cells efficiently by singlet-oxygen production when exposed to near infrared light.

Polyacrylamide-based nanoparticles offer numerous advantages, compared to other nanoplatforms. They are hydrophilic polymers which are physically similar to tissues, due to their relatively high water content and soft, flexible consistency. These nanoparticles show minimal aggregation or adsorption of proteins from body fluids, owing to their low interfacial tension and neutral surface charge. Also, the size of polyacrylamide-based nanoparticles is easily controlled by varying the synthesis conditions. Furthermore, polyacrylamide can be easily copolymerized with other monomers, so as to introduce functional groups as targeting tags, or to control their rate of biodegradation.

To apply nanoparticles to cells or tissues, the nanoplatform 's toxicity must be taken into account. Inverse microemulsion was used to fabricate blank or dye-encapsulating polyacrylamide nanoparticles in a water/hexane system ${ }^{6}$. The blank nanoparticle's toxicity to cells was then tested. 3-(4, 5-dimethylthiazol-2-yl)-2, 5-diphenyl tetrazolium bromide (MTT) was used to examine cell viability after $24 \mathrm{~h}$ incubation with various concentrations of blank polyacrylamide-based nanoparticles. Cell toxicity assays showed almost $100 \%$ cell viability, even after incubation with $5 \mathrm{mg} / \mathrm{mL}$ of polyacrylamide nanoparticles (Figure 1). This nontoxicity of polyacrylamide-based nanoparticles agrees with extensive studies on such carriers for drug delivery 7,8 .

In order to demonstrate that the nanoparticle matrix can prevent the dye from direct contact with the surroundings, fluorescent dye-encapsulating nanoparticles were used for leaching tests. $0.5 \mathrm{~mL}(1 \mathrm{mg} / \mathrm{mL})$ calcein AM (Molecular Probes) was dissolved in DMSO and further diluted into $1 \mathrm{~mL}$ water. This aqueous solution was used to encapsulate calcein into polyacrylamide-based nanoparticles by the previously mentioned synthetic method ${ }^{6}$. The nanoparticles were extensively washed with ethanol and water. Calcein AM is a fluorogenic esterase substrate that can be hydrolyzed to produce green fluorescence. The calcein fluorescence of the nanoparticles increased after hydrolysis but was not observed in the filtrate, indicating that the calcein dye remained within the matrix and did not leach out into the surrounding solution (supplementary information Figure 1S and Figure 2S). The protection of the cell from the dye molecules was further confirmed by incubating the dye-containing nanoparticles with rat $\mathrm{C} 6$ glioma cells. $1 \mathrm{mg} / \mathrm{mL}$ of calcein-encapsulating particles were incubated with rat C6 glioma cells for 1 hour. After that, the cells were washed with fresh medium and monitored by confocal fluorescence microscopy. No calcein fluorescence was observed within the cells, indicating again that the calcein was still encapsulated inside the polyacrylamide matrix without leaching. This was consistent with our previous leaching experiments and demonstrated that the nanoparticles can keep the dye molecules within the matrix and thus prevent direct dye contact with the surrounding. Therefore it is quite plausible that the nanoplatforms did not cause cellular toxicity. One should also note that the polym er's 
neutral surface, high hydrophilicity, low tendency for protein absorption, as well as its high water content, generally could enable these nanoparticles to evade cellular endocytosis. Furthermore, our polyacrylamide-based nanoparticles have high water solubility and therefore reduced cell uptake. To develop a TP-PDT nanoplatform, TMPyP was encapsulated into nanoparticles by a method similar to the previous one ${ }^{6}$. The nanoparticle's diameter was observed by SEM to be $20-30 \mathrm{~nm}$ (Figure 3S). Singlet oxygen generation by these particles was studied using a fluorescence-based method ${ }^{6}$. In a typical experiment, a $1 \mathrm{mg} / \mathrm{mL}$ nanoparticle suspension was repeatedly irradiated with a $780 \mathrm{~nm}$ laser source in the presence of $1 \mu \mathrm{M}$ of anthracene-dipropionic acid (ADPA). ADPA fluorescence spectra excited at 378 $\mathrm{nm}$ were then recorded after every irradiation. Results showed that the TP dye-encapsulating nanoparticles did produce significant amounts of singlet oxygen under $780 \mathrm{~nm}$ laser irradiation.

Although many new TP-PDT dyes were synthesized and were tested for their PDT effect ${ }^{5}$, there is no previous report of TP-PDT in living cells yet. This absence may be the result of the toxicity of these drugs to cells and/or their limited solubility in aqueous environment. To evaluate the nanoparticles' T P -PDT efficiency on the cellular level, a TP microscopy system was set up as shown in Figure 2. A pulsed laser source at $780 \mathrm{~nm}$ (Tsunami, Spectra Physics) was coupled to a 40X objective on an inverted microscope, exposing the dye to TP excitation. Reported irradiance values are calculated at the sample plane by multiplying the irradiance measured before the objective by the estimated transmission factor of the microscope system. A xenon lamp was used to excite fluorescent cell stains to indicate live cells (calcein, green) or dead cells (propidium iodide, red). Optical filters were inserted to restrict the excitation wavelength regions of both light sources.

We initially found that the cells were dying after exposure to xenon lamp light alone during cell viability imaging. Thus, conditions for xenon lamp control experiments were first established to maintain cell viability during microscopy monitoring. Rat C6 glioma cells on glass cover slips were placed in a temperature-controlled sample chamber at $37^{\circ} \mathrm{C}$ in culture medium and exposed to xenon lamp light for different durations. After insertion of the appropriate optical filter to block wavelengths below $450 \mathrm{~nm}$ (Figure 4S), the cells remained alive in all control experiments (Figure 3).

The laser fluence was a critical parameter for cell survival. Rat C6 glioma cells were exposed to $3 \mathrm{~W} / \mathrm{cm}^{2}$ of $780 \mathrm{~nm}$ laser light for 30 seconds $\left(100 \mathrm{~J} / \mathrm{cm}^{2}\right)$. Cells appeared to be damaged 10 minutes later. All exposed cells appeared to be dead after 30 minutes (Figure 5S). When the laser exposure was optimized to $100 \mathrm{~mW} / \mathrm{cm}^{2}$ for 1 second $\left(100 \mathrm{~mJ} / \mathrm{cm}^{2}\right)$, all exposed cells were still alive 30 minutes later. We used this lower approximate fluence for the next experiments (Figure 6S).

Under the above optimized experimental conditions, cells were incubated with $1 \mathrm{mg} / \mathrm{ml}$ of nanoparticles and the cells were monitored using fluorescence microscopy at different time points. Without nanoparticles, all cells were viable even after 120 minutes. Cells incubated with TMPyP-encapsulating nanoparticles started to show cell death 90 minutes after exposure to $100 \mathrm{~mW} / \mathrm{cm}^{2}$ pulsed light for 1 second $\left(100 \mathrm{~mJ} / \mathrm{cm}^{2}\right.$ ) (Figure $7 \mathrm{~S}$ ). When the exposure time was extended to about a minute $\left(10 \mathrm{~J} / \mathrm{cm}^{2}\right)$, cells started to die 30 minutes later and most exposed cells were dead after 120 minutes (Figure 4). The exposure time can be further optimized if necessary. These results show that TP-PDT was an effective tool for killing cells. We note that the nanoparticle's photo-toxicity was only triggered by exposure to light, specifically to low-power pulsed near-infrared laser illumination over a short time period.

The above test-tube and in-vitro results indicate that polyacrylamide-based nanoparticles are feasible platforms for TP-PDT. The relatively small size of these nanoparticles facilitates the diffusion of singlet oxygen from particle to cell, though even much larger polyacrylamide 
particles also exhibited efficient photo-toxicity in single-photon PDT experiments ${ }^{9}$. Because the biocompatible nanoplatform is not taken up by $\mathrm{C} 6$ glioma cells or other cell lines, it is expected that non-specific cell binding would be reduced. In conclusion, we have demonstrated that toxic drugs can be encapsulated into a neutral, hydrophilic matrix by microemulsion so as to avoid drug toxicity to cell cultures. This non-toxic matrix is biologically inert and is not usually ingested by endocytosis or other internalization mechanisms. Further modification of the nanoplatform with cancer surface biomarkers such as folic acid or other anti-cancer antibodies could guide the particle to specifically targeted cancer cells with less non-specific damage ${ }^{10}$. As near infrared TP excitation can give deeper tissue imaging there is no doubt that NP-TP-PDT will enable deeper tissue photodynamic therapy ${ }^{11}$. Our results demonstrate that, while safe, this TP-PDT nanoplatform does kill glioma cancer cells in vitro and may thus have potential for application to deep tissue therapy.

\section{Supplementary Material}

Refer to Web version on PubMed Central for supplementary material.

\section{Acknowledgements}

This work was supported by National Cancer Institute UIP contract N01-CO-37123.

\section{References}

1. (a) Dougherty TJ, Gomer CJ, Henderson BW, Jori G, Kessel D, Korbelik M, Moan J, Peng Q. J Natl Cancer Inst 1998;90:889-905. [PubMed: 9637138] (b) Sharman WM, Allen CM, van Lier JE. Drug Discovery Today 1999;4:507-517. [PubMed: 10529768] (c) Gross S, Gilead A, Scherz A, Meeman M, Salomon Y. Nature Medicine 2003;9:1327-1331. (d) Dennis EJGJ, Dolmans Dai Fukumura, Rakesh K Jain. Nature Reviews 2003;3:380-387.

2. Noske DP, Wolbers JG, Sterenborg HJCM. Clin Neurol Neurosurg 1991;93-4:293-307.

3. (a) Zebger I, Snyder JW, Andersen LK, Poulsen L, Gao Z, Lambert JDC, Kristiansen U, Ogilby PR. Photochemistry and Photobiology 2004;79:319-322. [PubMed: 15137507] (b) Romanova NA, Brovko LY, Moore L, Pometun E, Savitsky AP, Ugarova NN, Griffiths MW. Applied Environmental Microbiology 2003;69:6393-6398.

4. (a) Ogawa K, Hasegawa H, Inaba Y, Kobuke Y, Inouye H, Kanemitsu Y, Kohno E, Hirano T, Ogura S, Okura I. J Med Chem 2006;49:2276-2283. [PubMed: 16570924] (b) Karotki A, Khurana M, Lepock JR, Wilson BC. Photochemistry and Photobiology 2006;82:443-452. [PubMed: 16613497]

5. (a) Nielsen CB, Johnsen M, Arnbjerg J, Pittelkow M, McIlroy SP, Ogilby PR, Jrgensen M. J Org Chem 2005;70:7065-7079. [PubMed: 16122224] (b) Oar MA, Serin JM, Dichtel WR, Fréchet JM, Ohulchanskyy TY, Prasad PN. Chem Mater 2005;17:2267-2275. (c) Frederiksen PK, McIlroy SP, Nielsen CB, Nikolajsen L, Skovsen E, Jrgensen M, Mikkelsen KV, Ogilby PR. J Am Chem Soc 2005;127:255-269. [PubMed: 15631475] (d) Drobizhev M, Stepanenko Y, Dzenis Y, Karotki A, Rebane A, Taylor PN, Anderson HL. J Am Chem Soc 2004;126:15352-15353. [PubMed: 15563141]

6. (a) Moreno MJ, Monson E, Reddy RG, Rehemtulla A, Ross BD, Philbert M, Schneider RJ, Kopelman R. Sensors and Actuators B 2003;90:82-89. (b) Clark HA, Hoyer M, Philbert MA, Kopelman R. Anal Chem 1999;71:4831-4836. [PubMed: 10565274]

7. Ross B, Rehemtulla A, Koo YEL, Reddy R, Kim G, Behrend C, Buck S, Schneider RJ, Philbert MA, Weissleder R, Kopelman R. Proceedings of SPIE-The International Society for Optical Engineering 2004;5331:76-83.

8. Schneider, RJ. PhD thesis. University of Michigan; 2005.

9. Tang W, Kopelman R, Xu H, Philbert M. Photochemistry and Photobiology 2005;81:242-249. [PubMed: 15595888]

10. (a) Harrell JA, Kopelman R. Biophotonics International 2000;7:22-24. (b) Kopelman R, Philbert M, Koo Y-EL, Moffat BA, Reddy GR, McConville P, Hall DE, Chenevert TL, Bhojani MS, Buck SM, Rehemtulla A, Ross BD. J of Magnetism and Magnetic Materials 2005;293:404-410. 
11. Cahalan MD, Parker I, Wei SH, Miller MJ. Nature Reviews, Immunology 2002;2:872-880. 


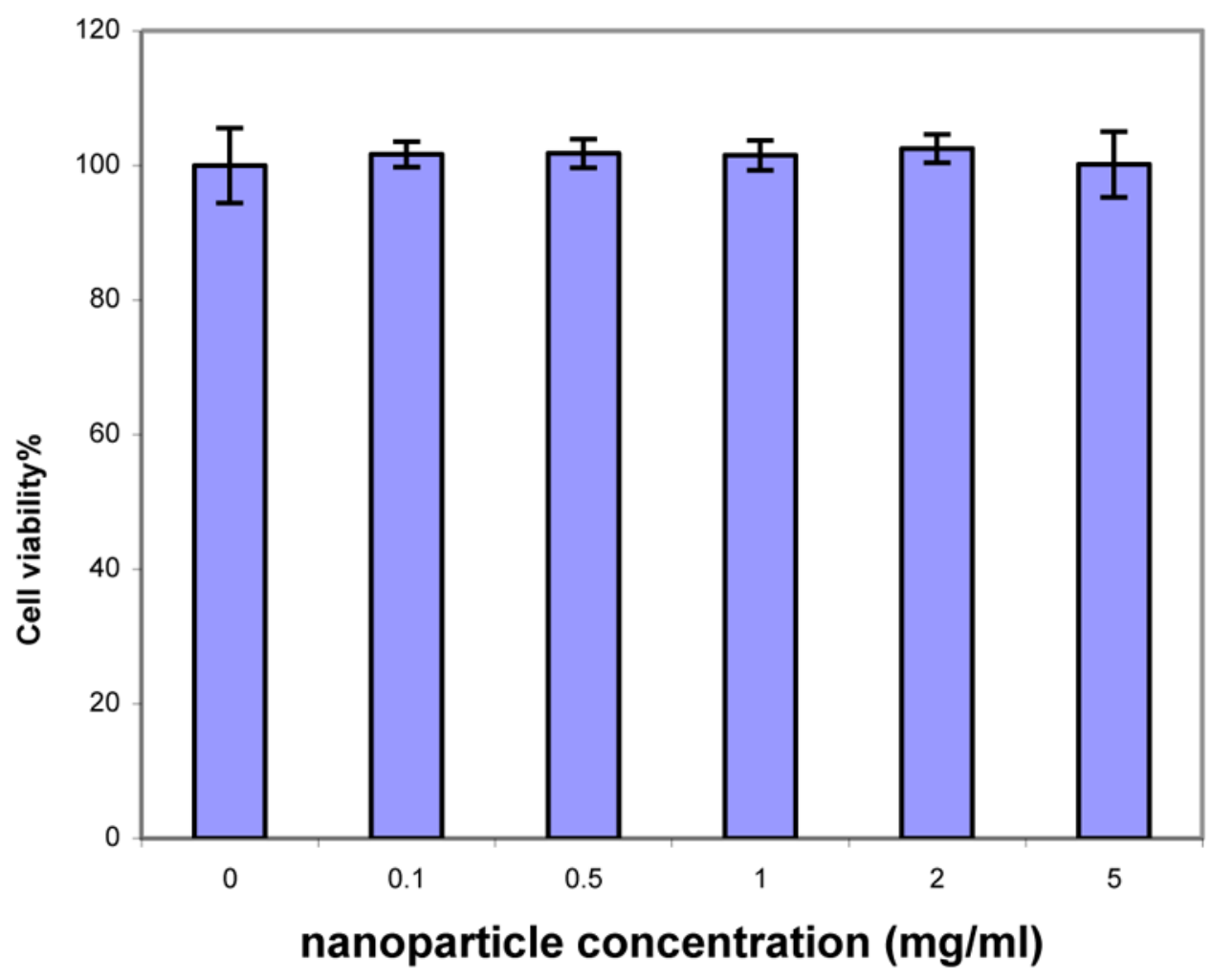

Figure 1.

Cell viability evaluated by MTT assay. Each calculation was an average of eight measurements. 


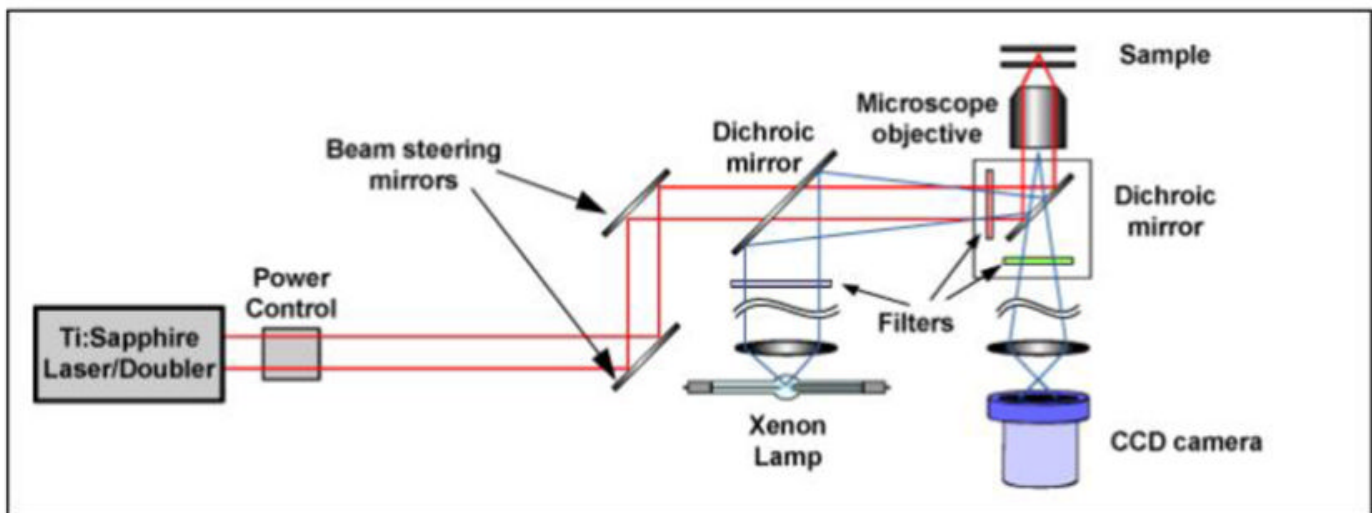

Figure 2.

The two-photon microscopy setup 


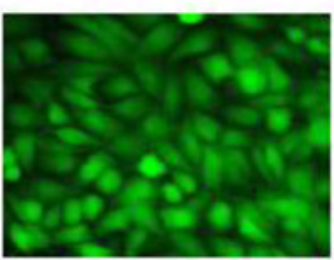

a

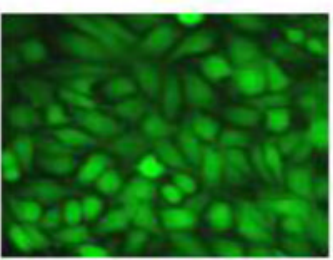

b

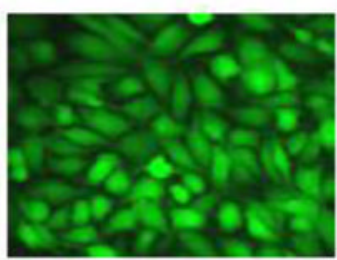

c

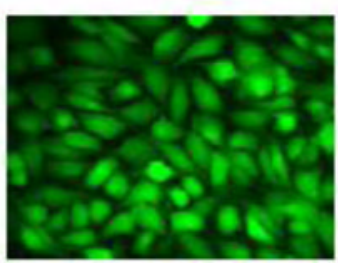

d

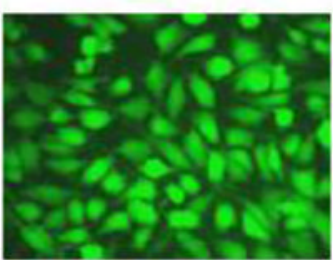

e

Figure 3.

Cell viability after exposing to filtered xenon lamp. a: before xenon lamp irradiation; b: after xenon lamp irradiation, 0 minutes; c: after xenon lamp irradiation, 10 minutes; $\mathrm{d}$ : after xenon lamp irradiation, 30 minutes; e: after xenon lamp irradiation, 90 minutes. Cells remain viable up to 90 minutes after exposure. 


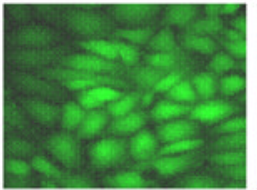

a

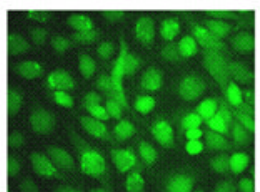

e

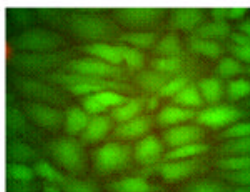

b

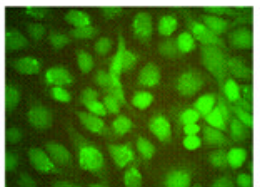

f

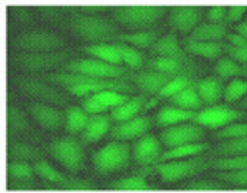

C

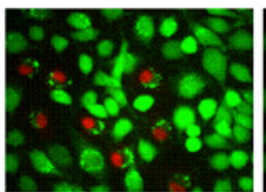

g

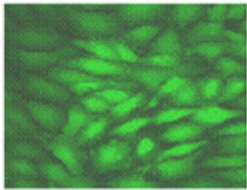

d

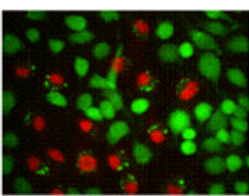

h

Figure 4.

a-d: Rat C6 glioma cells exposed to $100 \mathrm{~mW} / \mathrm{cm}^{2}, 780 \mathrm{~nm}$ laser for 1 minute. Images were taken at different time points. a: before irradiation; b: right after irradiation; c: 40 minutes after irradiation; d: 120 minutes after irradiation. e-h: Rat C6 glioma cells incubated with $1 \mathrm{mg} / \mathrm{ml}$ TMPyP-encapsulated nanoparticles, and exposed to $100 \mathrm{~mW} / \mathrm{cm}^{2} 780 \mathrm{~nm}$ laser for 1 minute. Images were taken at different time points. e: before irradiation; f: right after irradiation; g: 30 minutes after irradiation; h: 130 minutes after irradiation. 